\title{
Computational Study on Selective PDE9 Inhibitors on PDE9-Mg/Mg, PDE9-Zn/Mg, and PDE9-Zn/Zn Systems
}

\author{
Dakshinamurthy Sivakumar ${ }^{1} \oplus$, Sathishkumar Mudedla ${ }^{1}$, Seonghun Jang ${ }^{1}$, Hyunjun Kim ${ }^{2}$, Hyunjin Park ${ }^{2}$, \\ Yonwon Choi ${ }^{2}$, Joongyo $\mathrm{Oh}^{2}$ and Sangwook $\mathrm{Wu}^{1, *}$ \\ 1 R\&D Center, Pharmcadd, 221, 17 APEC-ro, Haeundae-gu, Busan 48060, Korea; sivabioinfo@gmail.com (D.S.); \\ mudedla@pharmcadd.com (S.M.); jwjang@pharmcadd.com (S.J.) \\ 2 R\&D Center, Huons co. Ltd., Ansan-si 15588, Korea; hjkim0206@huons.com (H.K.); \\ phj0630@huons.com (H.P.); cyw@huons.com (Y.C.); ohjg69@huons.com (J.O.) \\ * Correspondence: s.wu@pharmcadd.com; Tel.: +82-51-731-5688
}

check for updates

Citation: Sivakumar, D.; Mudedla, S.; Jang, S.; Kim, H.; Park, H.; Choi, Y.; Oh, J.; Wu, S. Computational Study on Selective PDE9 Inhibitors on PDE9-Mg/Mg, PDE9-Zn/Mg, and PDE9-Zn/Zn Systems. Biomolecules 2021, 11, 709. https://doi.org/ 10.3390/biom11050709

Academic Editor: Vladimir N. Uversky

Received: 8 April 2021

Accepted: 8 May 2021

Published: 10 May 2021

Publisher's Note: MDPI stays neutral with regard to jurisdictional claims in published maps and institutional affiliations.

Copyright: (c) 2021 by the authors. Licensee MDPI, Basel, Switzerland. This article is an open access article distributed under the terms and conditions of the Creative Commons Attribution (CC BY) license (https:// creativecommons.org/licenses/by/ $4.0 /)$.

\begin{abstract}
PDE9 inhibitors have been studied to validate their potential to treat diabetes, neurodegenerative disorders, cardiovascular diseases, and erectile dysfunction. In this report, we have selected highly potent previously reported selective PDE9 inhibitors BAY73-6691R, BAY73-6691S, 28r, 28s, 3r, 3s, PF-0447943, PF-4181366, and 4r to elucidate the differences in their interaction patterns in the presence of different metal systems such as $\mathrm{Zn} / \mathrm{Mg}, \mathrm{Mg} / \mathrm{Mg}$, and $\mathrm{Zn} / \mathrm{Zn}$. The initial complexes were generated by molecular docking followed by molecular dynamics simulation for $100 \mathrm{~ns}$ in triplicate for each system to understand the interactions' stability. The results were carefully analyzed, focusing on the ligands' non-bonded interactions with PDE9 in different metal systems.
\end{abstract}

Keywords: selective inhibitors; PDE9; molecular dynamics; metal complexes; BAY73-6691

\section{Introduction}

Cellular functions are regulated by the integration of intra and extracellular signals. Several signal transduction systems evolved to receive and process the signals; dysregulations lead to disruption in cellular functions and leads to diseases in humans [1]. One of the earliest identified cyclic nucleotide signalling systems is cAMP and cGMP. Phosphodiesterases (PDEs), a superfamily of enzymes, specifically hydrolyzes cyclic AMP and cyclic GMP, are detected in various tissues such as lungs, kidney, heart, brain, prostate, small intestine, prostate, bladder, and hematopoietic cells [2-5]. PDE isoenzymes differing by their substrate specificity are classified into 11 families, which encode several isoforms. PDEs- $(5,6,9)$ are cyclic GMP substrate-specific, whereas PDEs- $(4,7,8)$ are specific to cyclic AMP $[6,7]$.

PDEs were initially identified as the key regulators of intracellular cyclic nucleotide concentrations and later confirmed the role as host involving these secondary messengers in health and disease [8-10]. Each PDE holds its critical positions in regulating specific cyclic nucleotide signalling pathways and pathophysiological responses. Targeting particular PDEs by selective PDE inhibitors can improve the treatment efficacy. Some of the ongoing PDE targeting such as metabolic and cardiovascular diseases with PDE5 inhibitors, vascular remodelling with PDE1C and PDE3A inhibitors, and schizophrenia with PDE1 and PDE3A inhibitors, PDE7 inhibitors for inflammation, diabetes with PDE4 inhibitors and a combination of the above depend on the disease conditions [1].

In this work, we focused on PDE9 and several potent PDE9 inhibitors, which are already patented for the treatment of Diabetes mellitus, Alzheimer's disease and have shown potential for the treatment of obesity and cardiovascular diseases [11,12]. Although PDE9 inhibitors hold several advantages and sound therapeutic effects, minimal research is carried out compared to other PDE families. Here, we are analyzing the literature 
reported, highly potent PDE9 inhibitors BAY73-6691, PF-04447943, PF-4181366, 28 ( $\mathrm{r}$ and s), 3 ( $\mathrm{r}$ and $\mathrm{s}$ ), and $4 \mathrm{r}$ (Figure 1) [13-17].<smiles>Cc1nc2[nH]ncc2c(=O)[nH]1</smiles><smiles></smiles>
Compound 1<smiles>CC1CN(Cc2ncccn2)CC1c1nc2c(cnn2C2CCOCC2)c(=O)[nH]1</smiles>

Compound 4

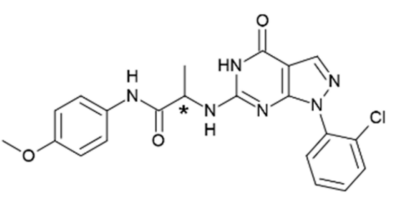

Compound 2<smiles>CC1CN(Cc2ccc3nccnc3c2)CC1c1nc2c(cnn2C2CCOCC2)c(=O)[nH]1</smiles>

Compound 5<smiles>COc1ccc(NC(=O)C(C)Nc2nc3c(cnn3C3CCCC3)c(=O)[nH]2)cc1</smiles>

Compound 3

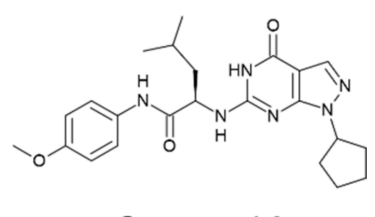

Compound 6

Figure 1. Selected literature reported chemical structures of PDE9 inhibitors [18]. Compound 1 (BAY73-6691), Compound 2 (28r and 28s), Compound 3 (3r and 3s), Compound 4 (PF-04447943), Compound 5 (PF-4181366), and Compound 6 (4r). The chiral carbon that makes two enantiomers were marked with symbol $(*)$. Common substructure included separately with numbering.

BAY73-6691 identified as a selective and potent PDE-9 inhibitor that can be used to treat neurodegenerative disorders such as Alzheimer's disease, as seen from the improved learning and memory in rats [18]. Additionally, in sickle cell disease, BAY73-6691 reduces neutrophil adhesion, inhibiting the vaso-occlusive process [4]. BAY73-6691 can block the PDE9 activity in the corpus cavernosum, which amplifies the Nitric Oxide -cGMP-mediated cavernosal responses, resulting in improvement in erectile dysfunction treatment [19]. PF04447943 was identified as a potent and selective inhibitor of the PDE9A completed phase$\mathrm{Ib}$ trials in Sickle disease patients to study the safety, PK/PD, and tolerability [20-22]. The study carried out in rats and mice showed improvement in cognition function and is currently in the clinical development for Alzheimer's disease [21].

Compound 3(3r) shows that it can act as a potential hypoglycemic agent by inhibiting mRNA expression of phosphoenolpyruvate carboxykinase (PEPCK) and Fructose 1,6-bisphosphatase (F-6-Pase) [17]. The other compounds show the effective inhibitory activity of PDE-9, as reported elsewhere [17]. Compound 5 (PF-4181366) reported a selective and highly potent inhibitor for PDE9A and it was identified that it could cause a dose-dependent increase in cGMP levels [15]. Compound 5 increases cGMP level in the striatum, hippocampus, and cortex with variations [23]. The rest of the compounds were also identified as PDE-9 inhibitors and were considered for the study.

\section{Materials and Methods}

\subsection{Protein Preparation}

The protein structure of Phosphodiesterase 9A was downloaded from the protein databank with Pdb id:4QGE [24]. PDE9 $(\mathrm{Zn} / \mathrm{Mg})$ was used from the above system, PDE9(Mg/Mg) and PDE9(Zn/Zn) developed by replacing Zn with Mg. Protein structures were prepared by correcting the bond orders, adding missing hydrogens, optimizing $\mathrm{H}$-bond with protonation states of residues at $\mathrm{pH} 7.0$, and restraining minimization for added hydrogens using OPLS2005 forcefield by protein preparation wizard [25]. We have performed DFT calculations for the ligands to minimize the geometry to get equilibrium bond lengths, bond angles and torsional angles for MD simulation. The charges derived using DFT methods are of high quality compared to other existing autogenerated programs based on low-level semiempirical methods. 


\subsection{Ligand Topology}

PDE9 inhibitors used in the study were initially optimized using the DFT method with Gaussian 16 [26] on B3LYP functionals [27] and 6-31G (d,p) basis set to calculate the electrostatic potential. The antechamber was run for the Gaussian output file to get GAFF atom types with RESP charges [28]. Atom types and all the needed ligand parameters were obtained from the above process.

\subsection{Molecular Docking}

Docking with explicit waters was performed with the Autodock4 Hydrated Docking method [29]. We used the crystal structure of 4QGE for explicit water position. Three water molecules were obtained, one interacting with the backbone of I403, N405, and E406, another interacting only with N405, and the other interacting with D402 and H256. All of those water molecules were positioned near the pyrazolo-pyrimidine moiety, typical for all docked compounds. We considered those as dummy atoms during the autodock hydrated docking procedure, as described in detail. After that, we removed the remaining water molecules and modified their positions to 4QGE. For other compounds, we aligned to the cocrystal structure of 4QGE and repeated the same procedure as described above for the dummy water atom. The binding grid was set, keeping the active site as the centre.

\subsection{Molecular Dynamics Simulations}

The stability of the complexes was studied by MD simulations using Gromacs2019 [30]. The Amber99sb-ildn force field was used for the protein parameters [31]. The protein-ligand complexes were solvated explicitly using the TIP3P water model inside the cubic box, and its size extends $0.1 \mathrm{~nm}$ away from the protein on the edges of the box in each direction. The system's overall charge was neutralized by adding a $0.1 \mathrm{M}$ salt concentration $\left(\mathrm{Na}^{+} \mathrm{Cl}^{-}\right)$. All the simulation was carried out in the GPU enabled Linux clusters. The entire system was minimized until the maximum force was less than $10 \mathrm{kj} / \mathrm{mol}$ with the maximum steps of 50,000 . The system was then equilibrated for $5 \mathrm{~ns}$ under NVT conditions with temperature coupling for two separate groups protein-ligand and water-ions, at $300 \mathrm{~K}$. The bonds to the hydrogen atoms were constrained using the Lincs algorithm [32]. The temperature and pressure were kept constant by the Berendsen thermostat and V-rescale, respectively $[33,34]$. The long-range electrostatic interactions were calculated using the particle mesh Ewald method (PME) [35]. The cutoff distances for Coulomb and van der Waals interactions were set as $1.2 \mathrm{~nm}$. The final production run was carried out for $100 \mathrm{~ns}$ in triplicate $(3 \times 100 \mathrm{~ns})$ at a temperature of $300 \mathrm{~K}$ and a pressure of 1 bar. More detailed methodology and analysis can be seen in our previous reports [36,37].

\subsection{MM/PBSA Binding Free Energy Calculation}

The g_mmpbsa package was used to calculate molecular mechanics (MM)/PoissonBoltzmann surface area (PBSA) free energy calculation [38]. The last $20 \mathrm{~ns}$ from the final production run were used for the analysis of the binding free energy. The calculated binding free energy contains three energetic terms, polar solvation energy (PSA), nonpolar solvation energy, and potential energy in a vacuum. Bonded (angle, bond, and dihedral) and non-bonded (electrostatic and van der Waal) interactions included in the vacuum's potential energy were calculated using $\mathrm{mm}$ forcefield parameters. The other two energetic terms, polar solvation energy and nonpolar solvation energy, were calculated using the Poisson-Boltzmann equation and the solvent-accessible surface area (SASA) model.

The binding free energy calculated by the following equation,

$$
\Delta \mathrm{G}_{\text {binding }}=\Delta \mathrm{G}_{\text {complex }}-\left(\Delta \mathrm{G}_{\text {protein }}+\Delta \mathrm{G}_{\text {ligand }}\right)
$$

$\Delta$ Gcomplex, $\Delta$ Gprotein, and $\Delta$ Gligand is the total free energy of the protein-ligand complex, isolated protein, and isolated ligand, respectively. 


\section{Results and Discussion}

\subsection{Docking of PDE-9 Inhibitors with PDE-9}

The PDE-9 structure docked with selected inhibitors to generate the complex. Compound 1 (both $R$ and $S$ ) holds the same dock score of $-9.5 \mathrm{kcal} / \mathrm{mol}$ and the identical interacting residues, hydrogen bond interactions with Gln453, and hydrophobic interactions with Phe251 and Phe456. Compound 2R with the docking score of $-11.3 \mathrm{kcal} / \mathrm{mol}$ shows hydrogen bond interactions with Ala452 and Gln453, hydrophobic interactions with Phe251 and Phe456. Compound $2(S)$ with a docking score of $-10.9 \mathrm{kcal} / \mathrm{mol}$ shows strong hydrogen bond interactions with Gln453 (with N6 and O10 atom of the pyrimidine ring) and Ala452 (with N11 atom) and signature $\pi-\pi$ interactions formed between Phe456 and both pyrimidine-pyrazole rings of the Compound 2S. Compound 3R with the docking score of $-10.7 \mathrm{kcal} / \mathrm{mol}$ shows $\pi-\pi$ interactions with Phe251 and Phe256, hydrogen bond interactions with Gln453 and Tyr424. However, Compound 3S, though it has a similar dock score $(-10.3 \mathrm{kcal} / \mathrm{mol})$, has a different interacting pattern. Hydrogen bond interactions with Gln453 and Ala452 and hydrophobic interactions with Phe456. Compound 4 with a docking score of $-10.7 \mathrm{kcal} / \mathrm{mol}$ shows hydrogen bond interactions with Gln453 and hydrophobic interactions with Phe251 and Phe456. Compound 5 with the highest dock score of $-12.0 \mathrm{kcal} / \mathrm{mol}$ and hydrogen bond interaction with $\mathrm{G} \ln 453$ and hydrophobic interactions with Phe251 and Ph3456. Compound 6 with a docking score of $-9.3 \mathrm{kcal} / \mathrm{mol}$ has hydrogen bond interactions with Ala452 and Gln453, also hydrophobic interactions with Phe456 (Table 1).

Table 1. Molecular docking and interacting residues along with the score for all the complexes and available enantiomers.

\begin{tabular}{|c|c|c|c|}
\hline Compound ID & Enantiomer & Docking Score (kcal/mol) & Interacting Residues * \\
\hline Compound $\mathbf{1}$ & $\mathrm{R}$ & -9.5 & F251, Q453, F456 \\
\hline Compound 1 & S & -9.5 & F251, Q453, F456 \\
\hline Compound 2 & $\mathrm{R}$ & -11.3 & $\mathrm{~F} 251, \mathrm{~A} 452, \mathrm{Q} 453, \mathrm{~F} 456$ \\
\hline Compound 2 & $S$ & -10.9 & A452, Q453, F456 \\
\hline Compound 3 & $\mathrm{R}$ & -10.7 & $\mathrm{~F} 251, \mathrm{Y} 424, \mathrm{Q} 453, \mathrm{~F} 456$ \\
\hline Compound 3 & S & -10.3 & A452, Q453, F456 \\
\hline Compound 4 & $\mathrm{n} / \mathrm{a}$ & -10.7 & F251, Q453, F456 \\
\hline Compound 5 & $\mathrm{n} / \mathrm{a}$ & -12.0 & $\mathrm{~F} 251, \mathbf{Q} 453, \mathrm{~F} 456$ \\
\hline Compound 6 & $\mathrm{n} / \mathrm{a}$ & -9.3 & A452, Q453, F456 \\
\hline
\end{tabular}

* Hydrogen bond residues are highlighted in bold.

\subsection{Interaction Details Based on the Simulation Results}

3.2.1. Compound 1 (BAY73-6691 $-R$ and $S$ ) in PDE-9 Zn/Mg, PDE-9 Mg/Mg, and PDE-9 Zn/Zn

Compound 1 (BAY73-6691 $(R)$ ) retains the native interaction in both PDE-9 Zn/Mg, $\mathrm{Mg} / \mathrm{Mg}$, and $\mathrm{Zn} / \mathrm{Zn}$ models. The $\mathrm{O}$ and adjacent $\mathrm{N}$ atom of the pyrimidine ring form hydrogen bond interactions with the Gln453, and the pyrazolo-pyrimidine ring forms $\pi-\pi$ stacking with Phe456 (Figure 2) (Table 2). Gln453 forms the hydrogen bond interactions for more than $90 \%$ of the simulation time in all three cases (Figure 3 ). 

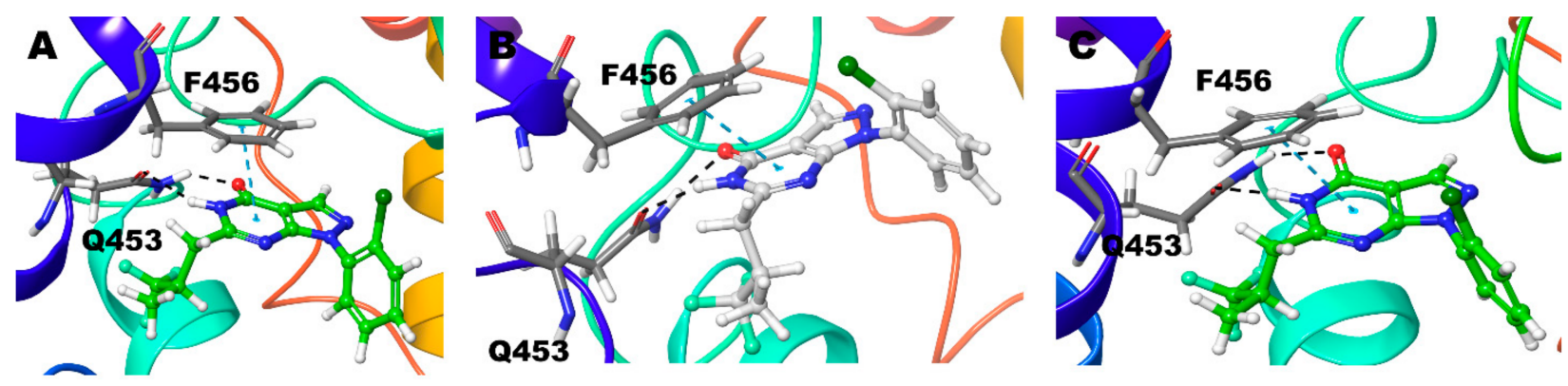

Figure 2. Non-bonded interactions of Compound 1(R) in (A) PDE9 Zn/Mg (B) PDE9 Mg/Mg (C) PDE9 Zn/Zn.

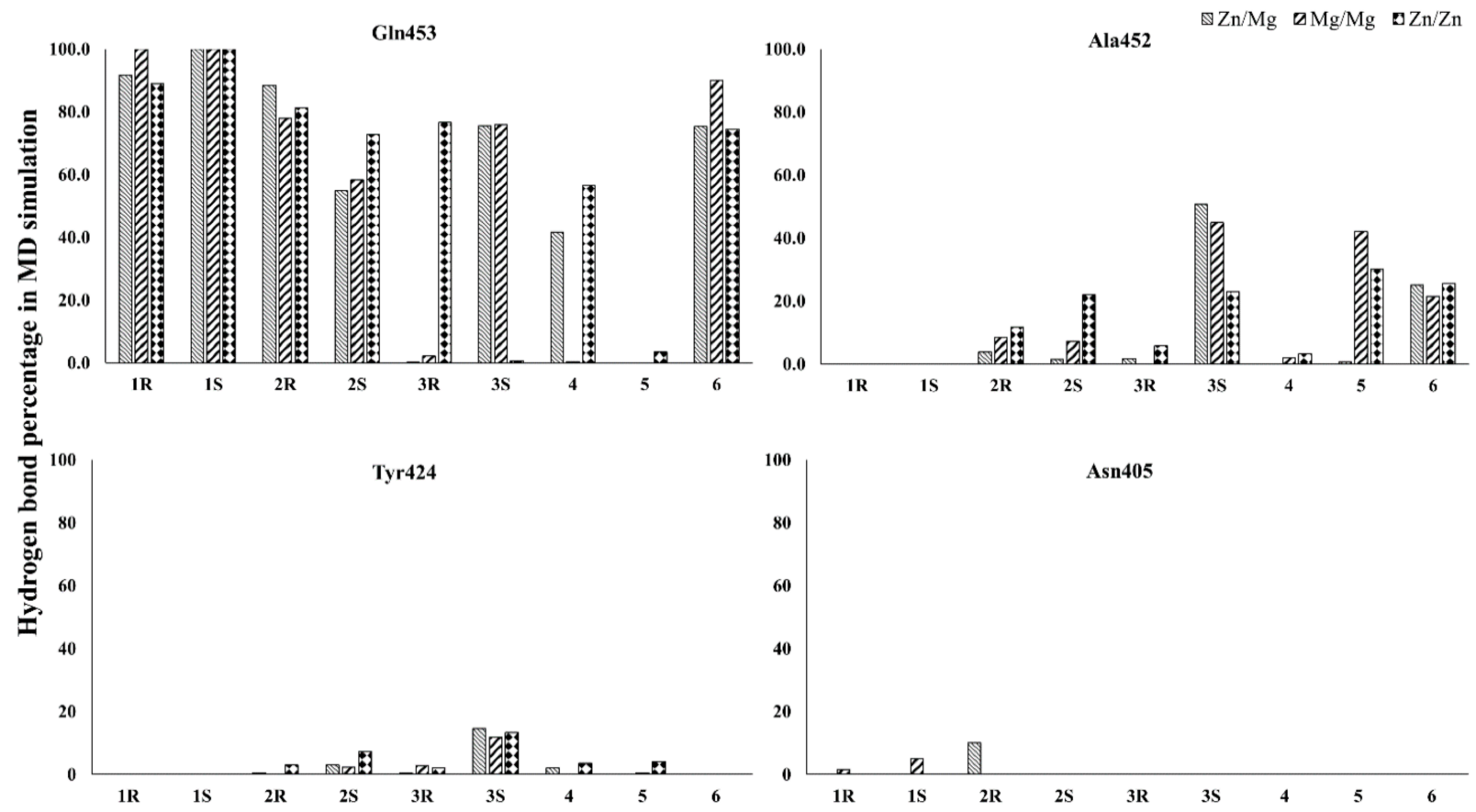

Figure 3. The strength of the hydrogen bond interactions between the critical residues of PDE-9 (in $\mathrm{Zn} / \mathrm{Mg}, \mathrm{Mg} / \mathrm{Mg}$, and $\mathrm{Zn} / \mathrm{Zn}$ ) and the compounds was monitored throughout the simulations.

Compound 1 (BAY73-6691 (S)) in the $\mathrm{Zn} / \mathrm{Mg}$ model follows similar interactions as above; in the $\mathrm{Mg} / \mathrm{Mg}$ model similar interaction and additional hydrogen bond interaction occurs towards Asn405. Still, Zn/Zn model holds the same hydrogen bond interaction as the $\mathrm{Zn} / \mathrm{Mg}$ model, but the signature $\pi-\pi$ stacking with Phe 456 was missing (Figure 4) (Table 2). The S-conformer of the Compound $\mathbf{1}$ forms a hydrogen bond with active site residue Gln 453 for whole $(100 \%)$ simulation in all the cases and additionally $5 \%$ of the simulation time with Asn405 in Mg/Mg case (Figure 3).
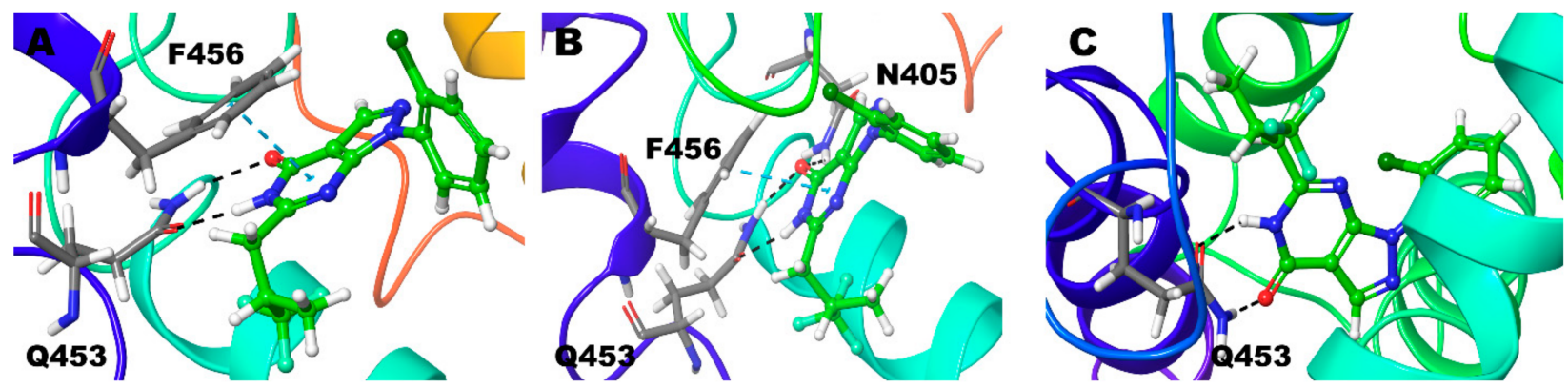

Figure 4. Non-bonded interactions of Compound 1(S) in (A) PDE9 Zn/Mg (B) PDE9 Mg/Mg (C) PDE9 Zn/Zn. 
Table 2. Inter-molecular interactions observed in the molecular dynamics studied in different systems.

\begin{tabular}{|c|c|c|c|}
\hline $\begin{array}{l}\text { Compound } \\
\text { ID/Enantiomer }\end{array}$ & Metal System & $\begin{array}{l}\text { Hydrogen Bond } \\
\text { Interactions }\end{array}$ & $\begin{array}{l}\text { Hydrophobic } \\
\text { Contacts }\end{array}$ \\
\hline \multirow{3}{*}{ Compound $1(R)$} & $\mathrm{Zn} / \mathrm{Mg}$ & Q453 & F456 \\
\hline & $\mathrm{Mg} / \mathrm{Mg}$ & Q453 & F456 \\
\hline & $\mathrm{Zn} / \mathrm{Zn}$ & Q453 & F456 \\
\hline \multirow{3}{*}{ Compound $\mathbf{1}(S)$} & $\mathrm{Zn} / \mathrm{Mg}$ & Q453 & F456 \\
\hline & $\mathrm{Mg} / \mathrm{Mg}$ & Q453, N405 & F456 \\
\hline & $\mathrm{Zn} / \mathrm{Zn}$ & Q453 & No Interactions \\
\hline \multirow{3}{*}{ Compound $2(R)$} & $\mathrm{Zn} / \mathrm{Mg}$ & Q453, A452, N405 & F456 \\
\hline & $\mathrm{Mg} / \mathrm{Mg}$ & Q453, A452 & F456 \\
\hline & $\mathrm{Zn} / \mathrm{Zn}$ & Q453, A452 & Y424 \\
\hline \multirow{3}{*}{ Compound 2 (S) } & $\mathrm{Zn} / \mathrm{Mg}$ & Q453, Y424 & F456, H368 \\
\hline & $\mathrm{Mg} / \mathrm{Mg}$ & Q453, A452 & F456, H368 \\
\hline & $\mathrm{Zn} / \mathrm{Zn}$ & Q453, A452 & F456 \\
\hline \multirow{3}{*}{ Compound $3(R)$} & $\mathrm{Zn} / \mathrm{Mg}$ & T302 & Y424, F441 \\
\hline & $\mathrm{Mg} / \mathrm{Mg}$ & No Interactions & No Interactions \\
\hline & $\mathrm{Zn} / \mathrm{Zn}$ & Q453 & F456 \\
\hline \multirow{3}{*}{ Compound $3(S)$} & $\mathrm{Zn} / \mathrm{Mg}$ & Q453, A452 & F456 \\
\hline & $\mathrm{Mg} / \mathrm{Mg}$ & Q453, A452, Y424 & F456 \\
\hline & $\mathrm{Zn} / \mathrm{Zn}$ & Y424, A452, F456 & F456 \\
\hline \multirow{3}{*}{ Compound 4} & $\mathrm{Zn} / \mathrm{Mg}$ & Q453 & F456, F441 \\
\hline & $\mathrm{Mg} / \mathrm{Mg}$ & No Interactions & F456 \\
\hline & $\mathrm{Zn} / \mathrm{Zn}$ & Q453 & F456 \\
\hline \multirow{3}{*}{ Compound 5} & $\mathrm{Zn} / \mathrm{Mg}$ & No Interactions & No Interactions \\
\hline & $\mathrm{Mg} / \mathrm{Mg}$ & A452 & F441 \\
\hline & $\mathrm{Zn} / \mathrm{Zn}$ & A452 & F456, F441 \\
\hline \multirow{3}{*}{ Compound 6} & $\mathrm{Zn} / \mathrm{Mg}$ & Q453, A452 & F456 \\
\hline & $\mathrm{Mg} / \mathrm{Mg}$ & Q453, A452 & F456 \\
\hline & $\mathrm{Zn} / \mathrm{Zn}$ & Q453, A452 & F456 \\
\hline
\end{tabular}

3.2.2. Compound 2 (28R and 28S) in PDE-9 Zn/Mg, PDE-9 Mg/Mg, and PDE-9 Zn/Zn

In the 28R-PDE- $\mathrm{Zn} / \mathrm{Mg}$ complex, the N6 atom of the pyrimidine ring shows strong hydrogen bond interaction only with Gln453. N11atom, linked with the C7 atom of the pyrimidine ring, shows hydrogen bond interactions with both Gln453 and Ala452. Likewise, the $\mathrm{O} 10$ atom (attached with the $\mathrm{C} 5$ atom of the pyrimidine ring) shows strong hydrogen bond interaction with both Gln453 and Asn 405 . The signature $\pi-\pi$ stacking of the pyrimidine ring and Phe456 was maintained in the simulation (Figure 5A) (Table 2). Gln 453 forms hydrogen bond for $88 \%$ of the simulation time and Asn 405 for $10 \%$ of the simulation time, and Ala452 forms $4 \%$ of the simulation time (Figure 3). 


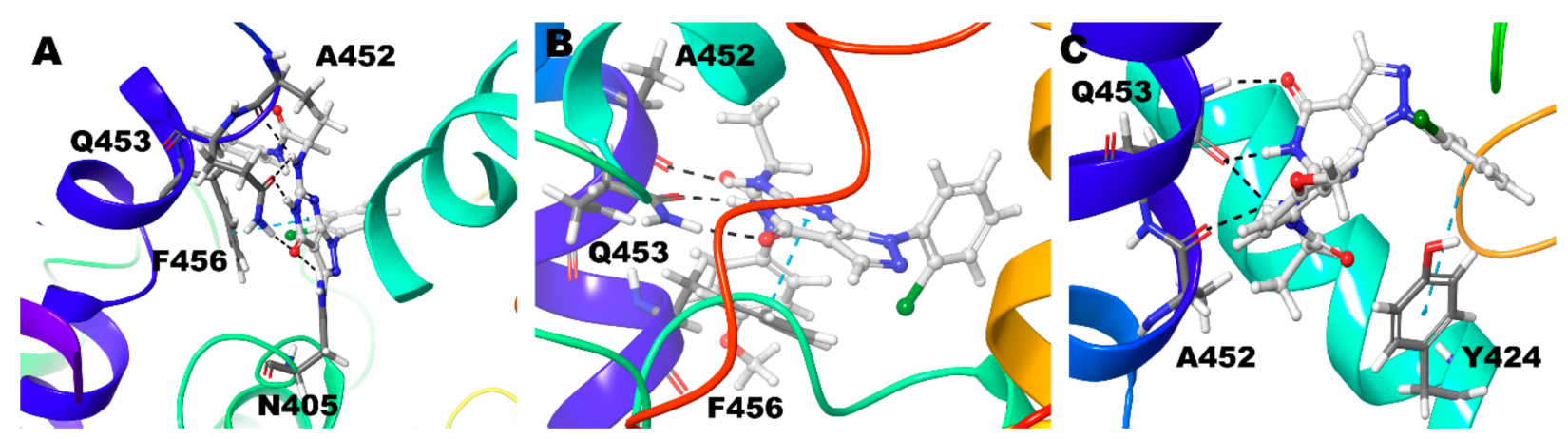

Figure 5. Non-bonded interactions of Compound 2 (R) in (A) PDE9 Zn/Mg (B) PDE9 Mg/Mg (C) PDE9 Zn/Zn.

In Compound 2R-PDE-Mg/Mg complex, though similar interactions were observed as in the $\mathrm{Zn} / \mathrm{Mg}$ complex, it seems as if the intensity of the interactions is reduced. N6 atom of the pyrimidine ring, along with the $\mathrm{O} 10$ shows hydrogen bond interaction with the Gln453. In this $\mathrm{O} 10$ atom interaction, it is seen only with Gln453 and not with Asn405, as seen in $\mathrm{Zn} / \mathrm{Mg}$ system. Similarly, the N11 atom shows hydrogen bond interaction only with Ala452 and not with Gln453, as we observed in the $\mathrm{Zn} / \mathrm{Mg}$ system. The signature $\pi-\pi$ stacking of the pyrimidine ring and Phe456 was maintained in this simulation (Figure 5B) (Table 2). Gln453 and Ala452 form hydrogen bonds with the compound for $78 \%$ and $8 \%$ of the simulation time (Figure 3).

In Compound 2R-PDE-Zn/Zn complex, very similar interactions were observed as in the $\mathrm{Mg} / \mathrm{Mg}$ complex with only additional $\pi-\pi$ interaction of Tyr424 with phenyl ring substituted the N1 atom of the pyrazole (Figure 5C) (Table 2). In nearly $81 \%$ of the simulation time Gln453 forms hydrogen bond, 12\% of the time with Ala452, and less than 3\% with Tyr424 (Figure 3).

In Compound 2S, PDE- $\mathrm{Zn} / \mathrm{Mg}$, and $\mathrm{Mg} / \mathrm{Mg}$ complex, the $\mathrm{N6}$ atom of the pyrimidine ring and the $\mathrm{O} 10$ show hydrogen bond interaction with the Gln453 (Figure 6A). The compound also forms additional hydrogen bond interaction with Tyr424 in $\mathrm{Zn} / \mathrm{Mg}$ model and with Ala452 in Mg/Mg model (Figure 6B). $\pi-\pi$ stacking was observed between pyrimidine ring, phenyl ring substituted at N1 atom of the pyrazole with Phe456 and His 368, respectively. In the $\mathrm{Zn} / \mathrm{Zn}$ model, there are similar interactions to the above cases, except no hydrophobic interaction was observed with His368 (Figure 6C) (Table 2). Gln453 shows interactions around $55 \%$ of the simulation time in the $\mathrm{Zn} / \mathrm{Mg}$ and $\mathrm{Mg} / \mathrm{Mg}$ case, whereas, in $\mathrm{Zn} / \mathrm{Zn}$, the interaction lasts more than $73 \%$ of the simulation time. Similarly, Tyr424 shows 2 to $3 \%$ of the simulation time in the first two cases, but in $\mathrm{Zn} / \mathrm{Zn}$, it lasts $7 \%$. In the case of Ala452, short-lived interaction occurred with just $1.5 \%$ in $\mathrm{Zn} / \mathrm{Mg}$ and $7 \%$ in $\mathrm{Mg} / \mathrm{Mg}$, but 22\% simulation time in $\mathrm{Zn} / \mathrm{Zn}$ (Figure 3).
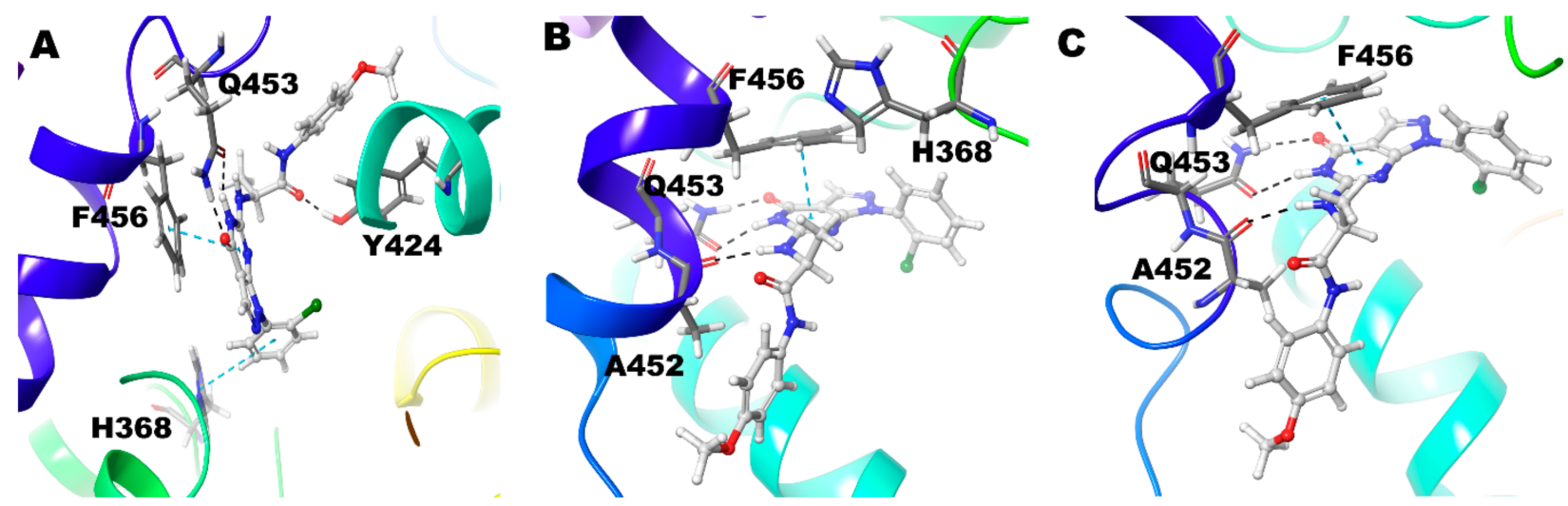

Figure 6. Non-bonded interactions of Compound 2(S) in (A) PDE9 Zn/Mg (B) PDE9 Mg/Mg (C) PDE9 Zn/Zn. 


\subsubsection{Compound 3 (3R and 3S) in PDE-9 Zn/Mg, PDE-9 Mg/Mg, and PDE-9 Zn/Zn}

Compound 3 (3R), $\mathrm{Zn} / \mathrm{Mg}$ shows no hydrogen bond interactions from its pyrimidinepyrazole moiety and no interactions with the active site residue Gln453. The pyrimidine ring forms $\pi-\pi$ interaction with other phenylalanine (Phe441), not the usual Phe456. Other ligand parts show hydrogen bond interaction with Thr302 and a $\pi-\pi$ interaction with Tyr424 (Figure 7A) (Table 2).
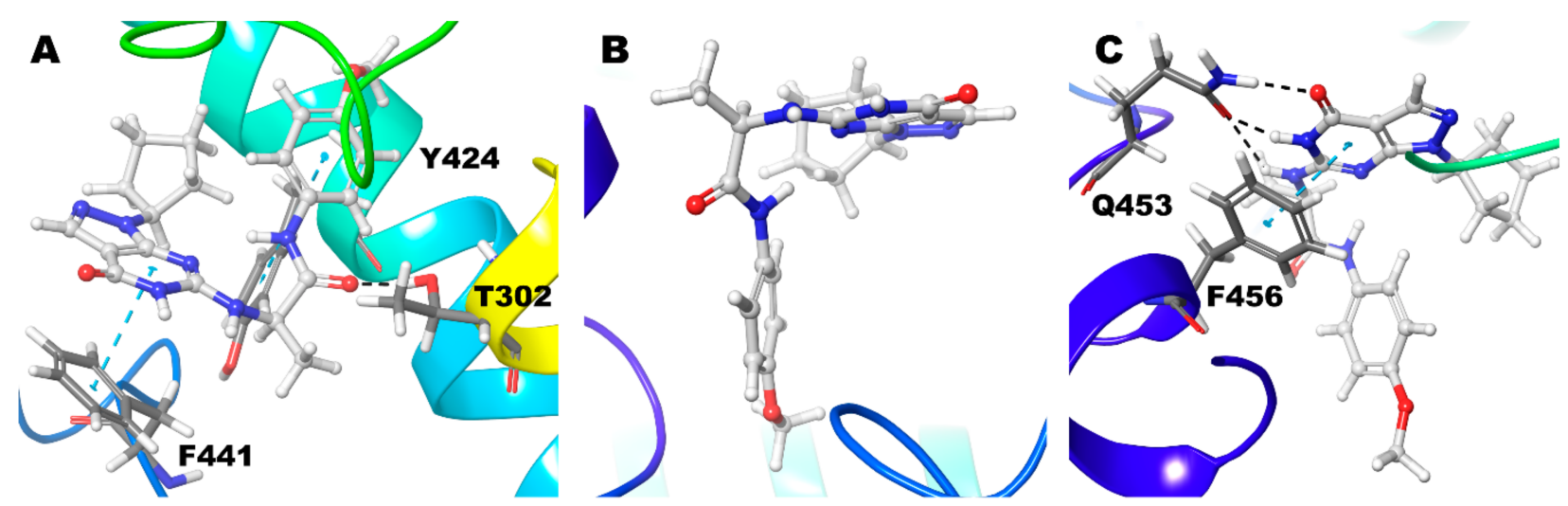

Figure 7. Non-bonded interactions of Compound 3(R) in (A) PDE9 Zn/Mg (B) PDE9 Mg/Mg (C) PDE9 Zn/Zn.

Interestingly, the Compound $3(3 R)-\mathrm{Mg} / \mathrm{Mg}$ model has no interactions observed (Figure 7B). In Zn/Zn model, the Gln453 shows strong hydrogen bond interactions with 3 different atoms (O10, N6, and N11) of the ligand. For more than $75 \%$ of the simulation time, the interactions were maintained (Figure 3 ). In this case, Signature $\pi-\pi$ stacking was observed between the pyrimidine ring and Phe456 (Figure 7C) (Table 2).

Compound 3 (3S), $\mathrm{Zn} / \mathrm{Mg}$ and $\mathrm{Mg} / \mathrm{Mg}$ model, strong hydrogen bond interaction N6 and $\mathrm{O} 10$ atom of the ligand with Gln453. Signature $\pi-\pi$ stacking was observed between both the pyrimidine, pyrazole ring and Phe456. Ala452 also shows hydrogen bond interactions with the ligand for $50 \%$ and $45 \%$ of the simulation time, respectively (Figure 3 ). Additionally, in $\mathrm{Mg} / \mathrm{Mg}$ model, Tyr424 shows hydrogen bond interaction with the N11 atom of ligand (Figure 8A,B). However, in the $\mathrm{Zn} / \mathrm{Zn}$ model, the results are quite different from the other two models. Gln453 hydrogen bond is missing; N6 atom of the pyrimidine ring forms hydrogen bond interaction with the Ala 452 for nearly $25 \%$ of the simulation time (Figure 3). The typical interaction with the previous two models is the signature $\pi-\pi$ stacking of Phe 456 with both the pyrimidine and pyrazole ring. The same amino acid also adds additional hydrogen bond interactions with the ligand. As we have seen in the $\mathrm{Mg} / \mathrm{Mg}$ model, we can see that the N11 atom of the ligand shows hydrogen bond interaction with the Tyr424 (Figure 8C).
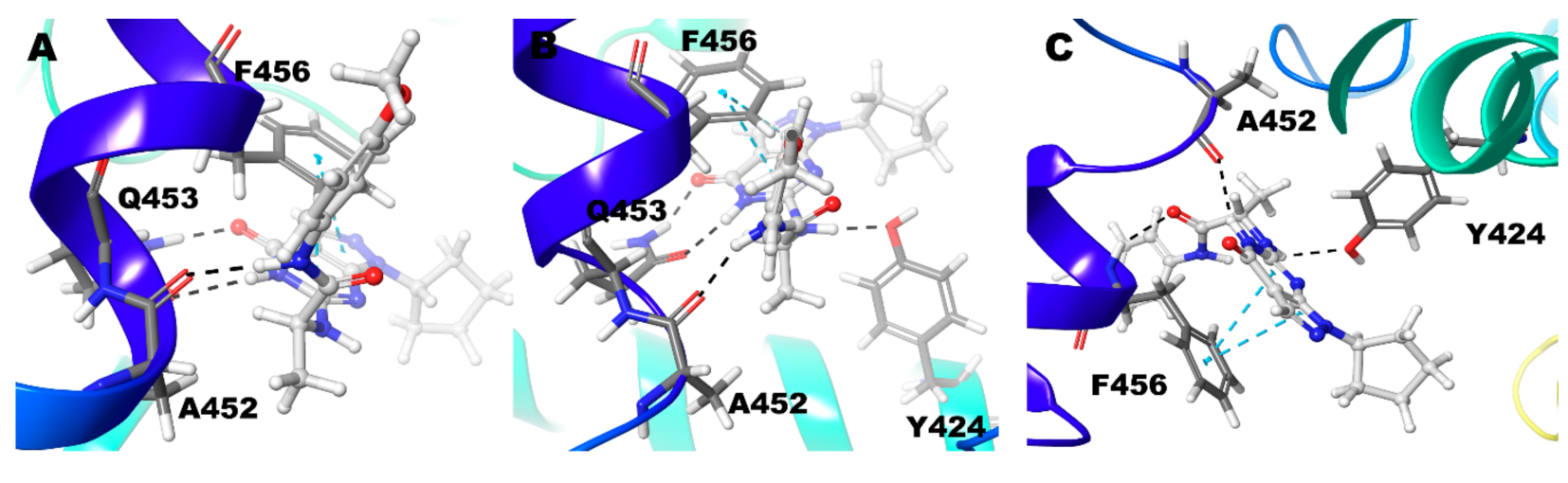

Figure 8. Non-bonded interactions of Compound 3 (S) in (A) PDE9 Zn/Mg (B) PDE9 Mg/Mg (C) PDE9 Zn/Zn. 
In contrast to Compound 3R, in which interaction with Gln453 of the $\mathrm{Zn} / \mathrm{Zn}$ model show more than $75 \%$ of the simulation time, in this case, its vice versa; $\mathrm{Zn} / \mathrm{Zn}$ has only negligible interactions. In contrast, the other two cases have interactions with the compound for more than $75 \%$ of the simulation time with Gln 453 . Tyr424 holds interactions with Compound $3 \mathrm{~S}$ in all three instances for around 10 to $15 \%$ of the simulation time (Figure 3 ) (Table 2).

\subsubsection{Compound 4 (PF-04447943) in PDE-9 Zn/Mg, PDE-9 Mg/Mg, and PDE-9 Zn/Zn}

Compound 4 with $\mathrm{Zn} / \mathrm{Mg}$ and $\mathrm{Zn} / \mathrm{Zn}$ model holds signature interactions, hydrogen bond interactions with Gln453, and $\pi-\pi$ stacking with Phe456 (Figure 9). Additionally, Phe441 shows $\pi-\pi$ stacking with the ligand only in the $\mathrm{Zn} / \mathrm{Mg}$ model. In the $\mathrm{Mg} / \mathrm{Mg}$ model, the ligand shows no hydrogen bond interactions but holds only one $\pi-\pi$ stacking between Phe456 and pyrimidine ring of the ligand (Figure 9) (Table 2). Hydrogen bond interaction with Gln453 for nearly $40 \%$ and $60 \%$ of the simulation time occurs only in $\mathrm{Zn} / \mathrm{Mg}$ and $\mathrm{Zn/Zn}$, respectively (Figure 3). Tyr424 and Ala452, in all cases, hold interactions only for a little time.
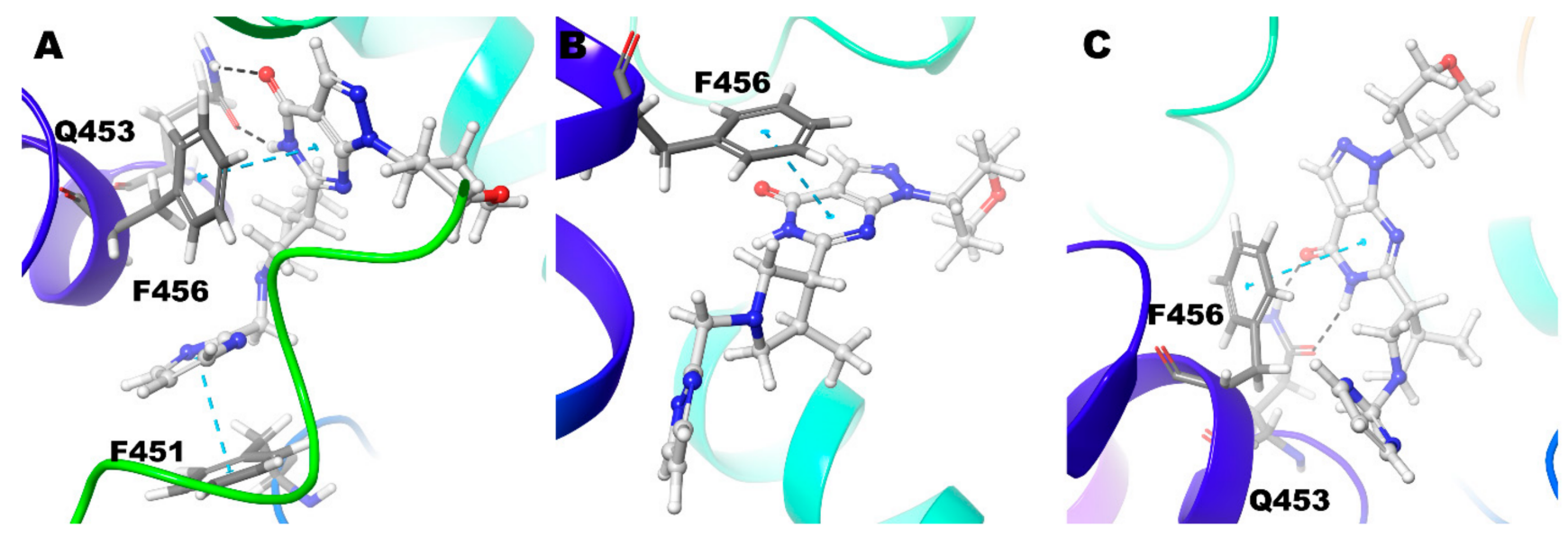

Figure 9. Non-bonded interactions of Compound 4 in (A) PDE9 Zn/Mg (B) PDE9 Mg/Mg (C) PDE9 Zn/Zn.

\subsubsection{Compound 5 (PF-4181366) in PDE-9 Zn/Mg, PDE-9 Mg/Mg and PDE-9 Zn/Zn}

Compound 5 in the $\mathrm{Zn} / \mathrm{Mg}$ model, with no significant interactions found (Figure 10A). Still, in $\mathrm{Mg} / \mathrm{Mg}$, though no signature interactions were found, Ala452 show hydrogen bond interactions with N6 atom and Phe441 showed $\pi-\pi$ interactions with the ligand (Figure 10B). Additionally, in the $\mathrm{Zn} / \mathrm{Zn}$ model, the N6 atom showed hydrogen bond interaction with Ala452; two $\pi-\pi$ interaction were observed, one with Phe441 and another one signature $\pi-\pi$ interaction-pyrazole ring with Phe456 (Figure 10C) (Table 2). Hydrogen bond interactions with Ala 452 in $\mathrm{Mg} / \mathrm{Mg}$ hold $42 \%$ and only $30 \%$ of the simulation time in the $\mathrm{Zn} / \mathrm{Zn}$ model (Figure 3). Other interactions were not observed for a significant duration. 

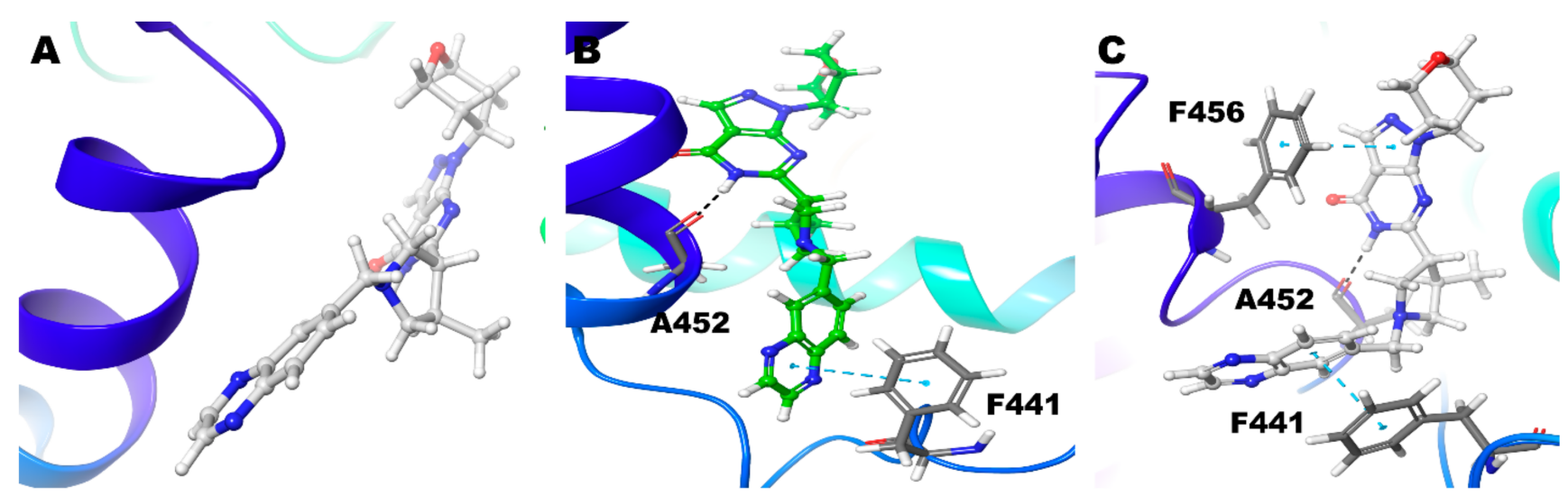

Figure 10. Non-bonded interactions of Compound 5 in (A) PDE9 Zn/Mg (B) PDE9 Mg/Mg (C) PDE9 Zn/Zn.

\subsubsection{Compound 6 (4r) in PDE-9 Zn/Mg, PDE-9 Mg/Mg and PDE-9 Zn/Zn}

In the $\mathrm{Zn} / \mathrm{Mg}$ model, hydrogen bond interaction was found between N6 and O10 atom of the ligand and Gln 453 for nearly $75 \%$ of the simulation time. N11 atom showed hydrogen bond interactions with Ala452 for almost one-fourth of the simulation time. Phe456 showed $\pi-\pi$ interactions with pyrimidine and pyrazole rings of Compound 6 (Figures 3 and 11A). It is very similar to the $\mathrm{Mg} / \mathrm{Mg}$ model but only with an additional hydrogen bond for Gln453 with the N11 atom of the ligand (Figure 11B) (Table 2). In the $\mathrm{Mg} / \mathrm{Mg}$ case, Gln 453 holds interaction for $90 \%$ of the simulation time, whereas with Ala452 only around $20 \%$ of the simulation time (Figure 3). In the $\mathrm{Zn} / \mathrm{Zn}$ model, similar to $\mathrm{Zn} / \mathrm{Mg}$ interaction with a tiny difference, Phe 456 shows $\pi-\pi$ interactions only with the ligand's pyrimidine ring (Figure 11C). Gln 453 holds nearly $75 \%$ of the simulation as in the case of $\mathrm{Zn} / \mathrm{Mg}$. Ala452 also has, similar to $\mathrm{Zn} / \mathrm{Mg}$, 25\% of the simulation time (Figure 3).
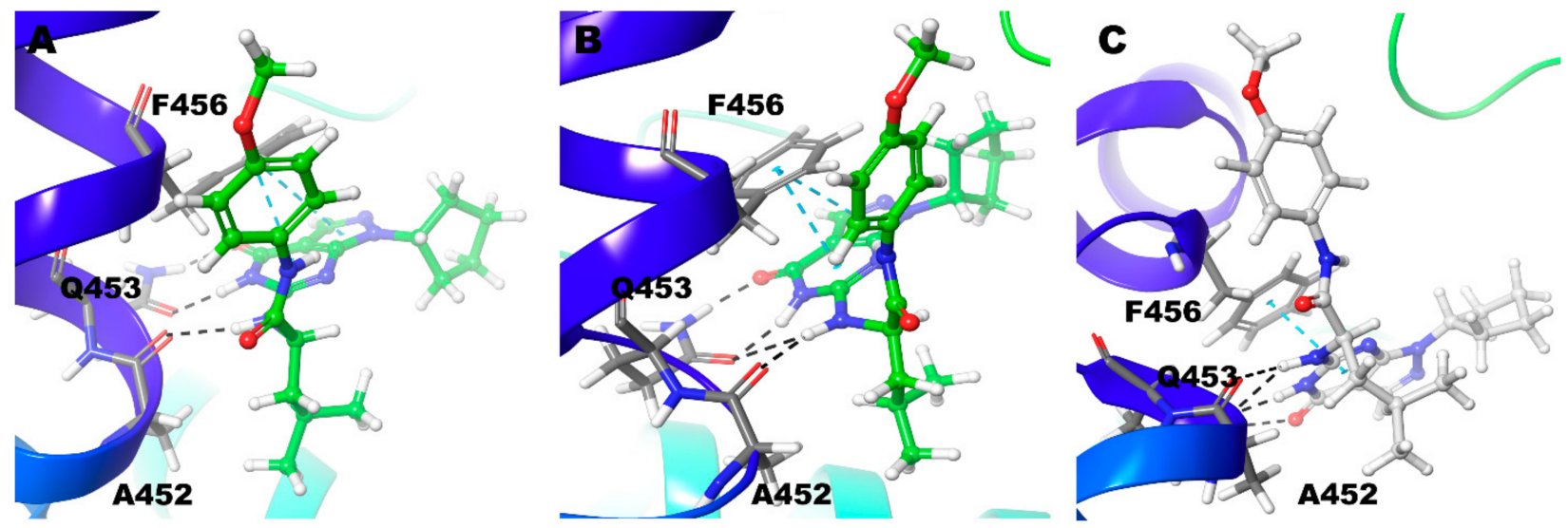

Figure 11. Non-bonded interactions of Compound 6 in (A) PDE9 Zn/Mg (B) PDE9 Mg/Mg (C) PDE9 Zn/Zn.

Based on the molecular dynamics interaction energy (Figure 12), Compound 6 seems more effective in binding with PDE9 irrespective of the metal system. Compound $2 \mathrm{R}$ is also almost on par with Compound 6 in terms of binding, except for a bit less in the $\mathrm{Mg} / \mathrm{Mg}$ system. Compound $3 S$ shows better binding on par with the above two compounds except for in the $\mathrm{Zn} / \mathrm{Zn}$ system. Compound $1 \mathrm{R}$ and $1 \mathrm{~S}$ have a lesser binding affinity compared to other compounds in all the systems. Some compounds show better binding in some metal systems and not in others such as Compound 3R, which has higher preferences for $\mathrm{Zn} / \mathrm{Zn}$ than $\mathrm{Zn} / \mathrm{Mg}$, and in Compound 4, which is not so favourable with thw $\mathrm{Mg} / \mathrm{Mg}$ system compared to the other two systems. The RMSD and RMSF plots obtained from the molecular dynamics results were shown in the Supplementary file (Figures S1-S18). 


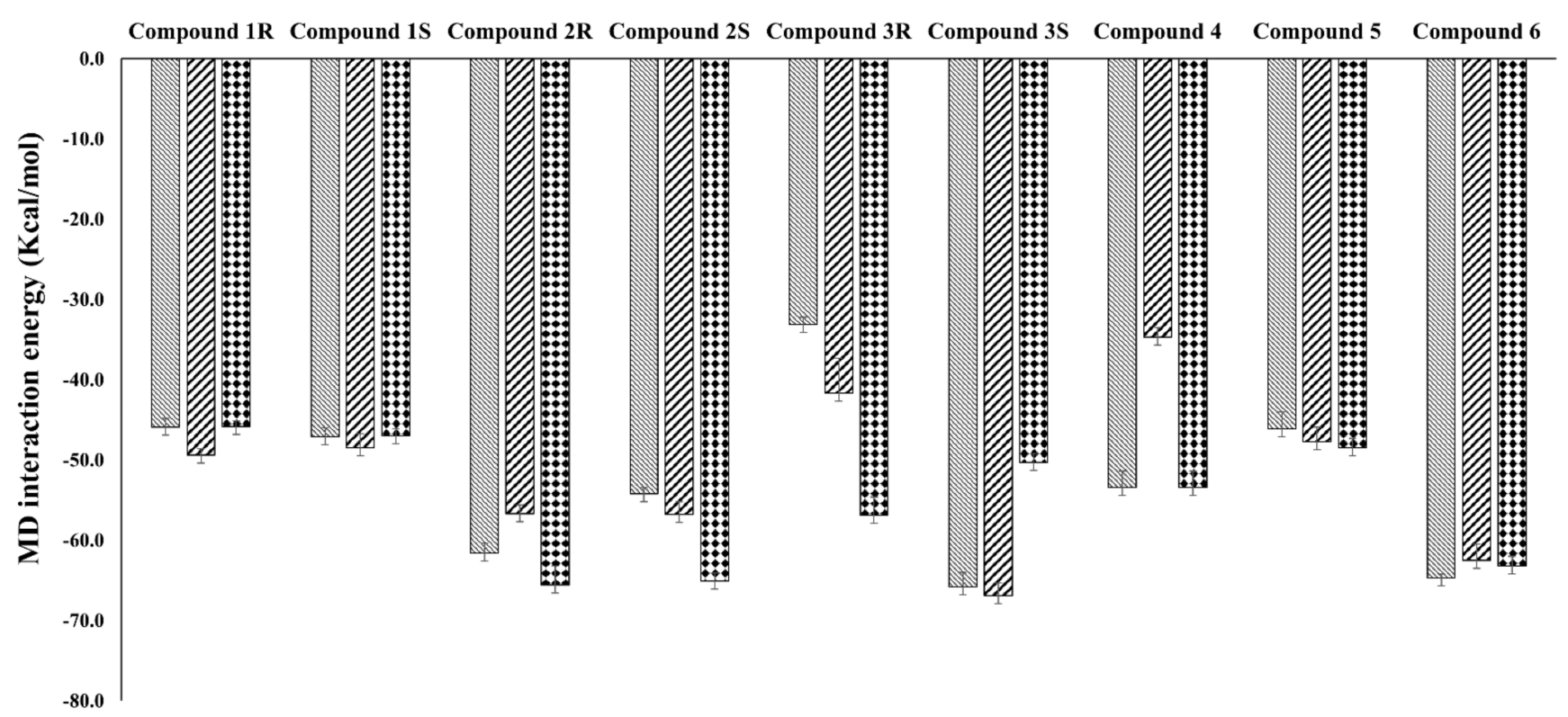

$\mathbb{Z} \mathrm{Zn} / \mathrm{Mg} \square \mathrm{Mg} / \mathrm{Mg}: \mathrm{Zn} / \mathrm{Zn}$

Figure 12. MD interaction energy was calculated for the compounds in PDE-9 (in $\mathrm{Zn} / \mathrm{Mg}, \mathrm{Mg} / \mathrm{Mg}$, and $\mathrm{Zn} / \mathrm{Zn}$ ).

Even the MM-PBSA based binding free energy analysis (Figure 13) also shows that Compound 6 is preferable in all three metal complexes. As seen in the MD interaction energy results, we have also noticed Compounds $1 R$ and $S$ least preference related to the Compound 6. Inclination towards the different metal complexes differs among the compounds, as Compound 6, 3S, and 2S are more inclined towards the $\mathrm{Zn} / \mathrm{Zn}$ metal systems. Compound 5 is more inclined towards the $\mathrm{Mg} / \mathrm{Mg}$ metal system, and Compounds $2 \mathrm{R}$ and $1 \mathrm{~S}$ are relatively higher in preference over the $\mathrm{Zn} / \mathrm{Mg}$ metal system than the other metal systems in PDE-9 inhibition. Compound 4 from the MM-PBSA results was omitted due to failure in the calculations due to unknown reasons after several attempts. The electrostatic interaction calculated using APBS calculation for Compound 3S and Compound $\mathbf{6}$ for three different metal systems (Figures S19 and S20) did not show much significant differences in the binding region.
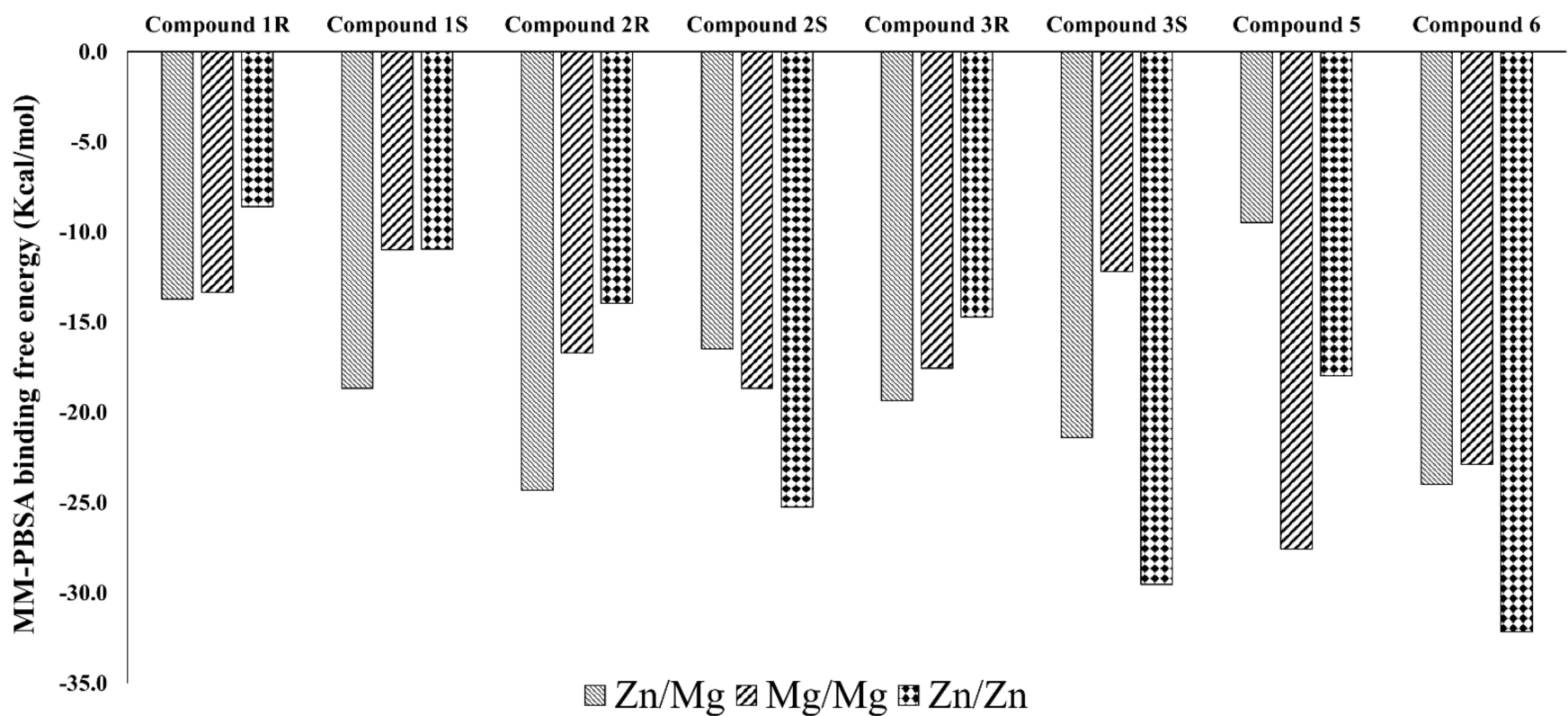

Figure 13. MM-PBSA binding free energy was calculated for the compounds in different metal systems. 


\section{Conclusions}

Overall, Compounds $1 R$ and $S, 2 R$, and Compound 6 show hydrogen bond interactions with active site residue Gln 453 for more than $75 \%$ of the simulation time irrespective of the metal systems. Interestingly, 3R shows only strong interactions with the $\mathrm{Zn} / \mathrm{Zn}$ system, whereas the other enantiomer of the same Compound $3 S$ show interactions except for $\mathrm{Zn} / \mathrm{Zn}$. Compound $\mathbf{2}$ shows significant interaction in all three cases but with a slightly higher preference over the $\mathrm{Zn} / \mathrm{Zn}$ system. Considering the interaction with Ala452, Compounds $3 S$ and $\mathbf{6}$ show relatively equal interactions in all three systems. Compound $\mathbf{5}$ also extends its interactions with Ala452, with the execption of in Zn/Mg. Ty424 and Asn405 interactions are less significant in terms of our MD results. Based on this result, we can see that Compound $\mathbf{6}$ shows a stronger preference to PDE-9 irrespective of the metal systems, which is also well aligned with our other analysis based on the MD interaction energy and MM-PBSA binding free energy studies. The purpose of this study is not to claim one of the compounds as best, as all the compounds have shown efficacy and selectivity, and some are in different phases of clinical trials. Here we show the significance of the metal system of the PDE-9 and its influence in altering the inhibitory effect of the protein. Further analysis at the QM level and experimental validations to understand the impact of the different metal systems, including Mn/Mn, in the PDE-9 with ligand binding are under progress in our lab.

Supplementary Materials: The following are available online at https://www.mdpi.com/article/ 10.3390/biom11050709/s1, Figure S1. C-alpha RMSD plot of PDE-9 (Mg/Mg, Zn/Mg, Zn/Zn) in complexed with Compound-1R; Figure S2. C-alpha RMSD plot of PDE-9 (Mg/Mg, Zn/Mg, Zn/Zn) in complexed with Compound-1S; Figure S3. C-alpha RMSD plot of PDE-9 (Mg/Mg, Zn/Mg, Zn/Zn) in complexed with Compound-2R; Figure S4. C-alpha RMSD plot of PDE-9 (Mg/Mg, Zn/Mg, Zn/Zn) in complexed with Compound-2S; Figure S5. C-alpha RMSD plot of PDE-9 (Mg/Mg, Zn/Mg, Zn/Zn) in complexed with Compound-3R; Figure S6. C-alpha RMSD plot of PDE-9 (Mg/Mg, Zn/Mg, Zn/Zn) in complexed with Compound-3S; Figure S7. C-alpha RMSD plot of PDE-9 (Mg/Mg, Zn/Mg, Zn/Zn) in complexed with Compound-4; Figure S8. C-alpha RMSD plot of PDE-9 (Mg/Mg, Zn/Mg, Zn/Zn) in complexed with Compound-5; Figure S9. C-alpha RMSD plot of PDE-9 (Mg/Mg, Zn/Mg, Zn/Zn) in complexed with Compound-6; Figure S10. Protein RMSF plot of PDE-9 (Mg/Mg, Zn/Mg, Zn/Zn) in complexed with Compound-6; Figure S11. Protein RMSF plot of PDE-9 (Mg/Mg, Zn/Mg, Zn/Zn) in complexed with Compound-6; Figure S12. Protein RMSF plot of PDE-9 (Mg/Mg, Zn/Mg, Zn/Zn) in complexed with Compound-6; Figure S13. Protein RMSF plot of PDE-9 (Mg/Mg, Zn/Mg, Zn/Zn) in complexed with Compound-6; Figure S14. Protein RMSF plot of PDE-9 (Mg/Mg, Zn/Mg, Zn/Zn) in complexed with Compound-6; Figure S15. Protein RMSF plot of PDE-9 (Mg/Mg, Zn/Mg, Zn/Zn) in complexed with Compound-6; Figure S16. Protein RMSF plot of PDE-9 (Mg/Mg, Zn/Mg, Zn/Zn) in complexed with Compound-6; Figure S17. Protein RMSF plot of PDE-9 (Mg/Mg, Zn/Mg, Zn/Zn) in complexed with Compound-6; Figure S18. Protein RMSF plot of PDE-9 (Mg/Mg, Zn/Mg, Zn/Zn) in complexed with Compound-6; Figure S19. Electrostatic interaction map using APBS calculation for the Compound-3S in all three different metal systems (Mg/Mg, Zn/Mg, Zn/Zn).; Figure S20. Electrostatic interaction map using APBS calculation for the Compound-6 in all three different metal systems ( $\mathrm{Mg} / \mathrm{Mg}$, Zn/Mg, Zn/Zn).

Author Contributions: Conceptualization, D.S. and S.W.; methodology, D.S.; S.M.; S.J.; validation, D.S.; S.M.; formal analysis, D.S.; S.M.; S.J.; data curation, DS; writing—original draft preparation, D.S.; writing—review and editing, D.S.; S.W.; H.K.; J.O.; visualization, D.S.; H.K.; H.P.; Y.C.; J.O.; supervision, S.W.; project administration, S.W.; funding acquisition, S.W.; All authors have read and agreed to the published version of the manuscript.

Funding: This research was funded by special initiative internal research funding of Pharmcadd.

Institutional Review Board Statement: Approved.

Informed Consent Statement: Not applicable.

Data Availability Statement: All data presented in the paper. 
Acknowledgments: The authors are thankfull to Taehyung Kwon (CEO), and Ilsang Yoon (R\&D Head), Junkoo Kim (CFO), Sunjang Kim (Executive Director), Jinha Hwang (Director-BD) for their support in different stages of the project.

Conflicts of Interest: The authors declare no conflict of interest.

\section{References}

1. Maurice, D.H.; Ke, H.; Ahmad, F.; Wang, Y.; Chung, J.; Manganiello, V.C. Advances in Targeting Cyclic Nucleotide Phosphodiesterases. Nat. Rev. Drug. Discov. 2014, 13, 290-314. [CrossRef] [PubMed]

2. Küthe, A.; Wiedenroth, A.; Mägert, H.J.; Uckert, S.; Forssmann, W.G.; Stief, C.G.; Jonas, U. Expression of Different Phosphodiesterase Genes in Human Cavernous Smooth Muscle. J. Urol. 2001, 165, 280-283. [CrossRef] [PubMed]

3. Wang, P.; Wu, P.; Egan, R.W.; Billah, M.M. Identification and Characterization of a New Human Type 9 CGMP-Specific Phosphodiesterase Splice Variant (PDE9A5). Differential Tissue Distribution and Subcellular Localization of PDE9A Variants. Gene 2003, 314, 15-27. [CrossRef]

4. Almeida, C.B.; Traina, F.; Lanaro, C.; Canalli, A.A.; Saad, S.T.O.; Costa, F.F.; Conran, N. High Expression of the CGMP-Specific Phosphodiesterase, PDE9A, in Sickle Cell Disease (SCD) and the Effects of Its Inhibition in Erythroid Cells and SCD Neutrophils. Br. J. Haematol. 2008, 142, 836-844. [CrossRef] [PubMed]

5. Nagasaki, S.; Nakano, Y.; Masuda, M.; Ono, K.; Miki, Y.; Shibahara, Y.; Sasano, H. Phosphodiesterase Type 9 (PDE9) in the Human Lower Urinary Tract: An Immunohistochemical Study. BJU Int. 2012, 109, 934-940. [CrossRef] [PubMed]

6. Conti, M.; Jin, S.L. The Molecular Biology of Cyclic Nucleotide Phosphodiesterases. Prog Nucleic Acid. Res. Mol. Biol. 1999, 63, 1-38. [CrossRef] [PubMed]

7. Bender, A.T.; Beavo, J.A. Cyclic Nucleotide Phosphodiesterases: Molecular Regulation to Clinical Use. Pharmacol. Rev. 2006, 58, 488-520. [CrossRef]

8. Conti, M.; Beavo, J. Biochemistry and Physiology of Cyclic Nucleotide Phosphodiesterases: Essential Components in Cyclic Nucleotide Signaling. Annu. Rev. Biochem. 2007, 76, 481-511. [CrossRef]

9. Francis, S.H.; Blount, M.A.; Corbin, J.D. Mammalian Cyclic Nucleotide Phosphodiesterases: Molecular Mechanisms and Physiological Functions. Physiol. Rev. 2011, 91, 651-690. [CrossRef]

10. Keravis, T.; Lugnier, C. Cyclic Nucleotide Phosphodiesterase (PDE) Isozymes as Targets of the Intracellular Signalling Network: Benefits of PDE Inhibitors in Various Diseases and Perspectives for Future Therapeutic Developments. Br. J. Pharmacol. 2012, 165, 1288-1305. [CrossRef]

11. Fryburg, D.; Gibbs, E. Treatment of Insulin Resistance Syndrome and Type 2 Diabetes with Pde9 Inhibitors 2003. Available online: https:/ / patentscope.wipo.int/search/en/detail.jsf?docId=WO2003037432 (accessed on 23 March 2021).

12. US20170173018 Substituted Imidazo [1,5-a]Pyrazines as PDE9 Inhibitors. Available online: https://patentscope.wipo.int/search/ en/detail.jsf?docId=US199414325\&docAn=15452827 (accessed on 23 March 2021).

13. Wunder, F.; Tersteegen, A.; Rebmann, A.; Erb, C.; Fahrig, T.; Hendrix, M. Characterization of the First Potent and Selective PDE9 Inhibitor Using a CGMP Reporter Cell Line. Mol. Pharmacol. 2005, 68, 1775-1781. [CrossRef]

14. Verhoest, P.R.; Proulx-Lafrance, C.; Corman, M.; Chenard, L.; Helal, C.J.; Hou, X.; Kleiman, R.; Liu, S.; Marr, E.; Menniti, F.S.; et al. Identification of a Brain Penetrant PDE9A Inhibitor Utilizing Prospective Design and Chemical Enablement as a Rapid Lead Optimization Strategy. J. Med. Chem. 2009, 52, 7946-7949. [CrossRef]

15. Verhoest, P.R.; Fonseca, K.R.; Hou, X.; Proulx-Lafrance, C.; Corman, M.; Helal, C.J.; Claffey, M.M.; Tuttle, J.B.; Coffman, K.J.; Liu, S.; et al. Design and Discovery of 6-[(3S,4S)-4-Methyl-1-(Pyrimidin-2-Ylmethyl)Pyrrolidin-3-Yl]-1-(Tetrahydro-2H-Pyran-4-Yl)-1,5Dihydro-4H-Pyrazolo[3,4-d]Pyrimidin-4-One (PF-04447943), a Selective Brain Penetrant PDE9A Inhibitor for the Treatment of Cognitive Disorders. J. Med. Chem. 2012, 55, 9045-9054. [CrossRef]

16. Meng, F.; Hou, J.; Shao, Y.-X.; Wu, P.-Y.; Huang, M.; Zhu, X.; Cai, Y.; Li, Z.; Xu, J.; Liu, P.; et al. Structure-Based Discovery of Highly Selective Phosphodiesterase-9A Inhibitors and Implications for Inhibitor Design. J. Med. Chem. 2012, 55, 8549-8558. [CrossRef]

17. Shao, Y.; Huang, M.; Cui, W.; Feng, L.-J.; Wu, Y.; Cai, Y.; Li, Z.; Zhu, X.; Liu, P.; Wan, Y.; et al. Discovery of a Phosphodiesterase 9A Inhibitor as a Potential Hypoglycemic Agent. J. Med. Chem. 2014, 57, 10304-10313. [CrossRef]

18. van der Staay, F.J.; Rutten, K.; Bärfacker, L.; DeVry, J.; Erb, C.; Heckroth, H.; Karthaus, D.; Tersteegen, A.; van Kampen, M.; Blokland, A.; et al. The Novel Selective PDE9 Inhibitor BAY 73-6691 Improves Learning and Memory in Rodents. Neuropharmacology 2008, 55, 908-918. [CrossRef]

19. da Silva, F.H.; Pereira, M.N.; Franco-Penteado, C.F.; De Nucci, G.; Antunes, E.; Claudino, M.A. Phosphodiesterase-9 (PDE9) Inhibition with BAY 73-6691 Increases Corpus Cavernosum Relaxations Mediated by Nitric Oxide-Cyclic GMP Pathway in Mice. Int. J. Impot. Res. 2013, 25, 69-73. [CrossRef]

20. Kleiman, R.J.; Chapin, D.S.; Christoffersen, C.; Freeman, J.; Fonseca, K.R.; Geoghegan, K.F.; Grimwood, S.; Guanowsky, V.; Hajós, M.; Harms, J.F.; et al. Phosphodiesterase 9A Regulates Central CGMP and Modulates Responses to Cholinergic and Monoaminergic Perturbation in Vivo. J. Pharmacol. Exp. Ther 2012, 341, 396-409. [CrossRef]

21. Hutson, P.H.; Finger, E.N.; Magliaro, B.C.; Smith, S.M.; Converso, A.; Sanderson, P.E.; Mullins, D.; Hyde, L.A.; Eschle, B.K.; Turnbull, Z.; et al. The Selective Phosphodiesterase 9 (PDE9) Inhibitor PF-04447943 (6-[(3S,4S)-4-Methyl-1-(Pyrimidin-2Ylmethyl)Pyrrolidin-3-Yl]-1-(Tetrahydro-2H-Pyran-4-Yl)-1,5-Dihydro-4H-Pyrazolo[3,4-d]Pyrimidin-4-One) Enhances Synaptic Plasticity and Cognitive Function in Rodents. Neuropharmacology 2011, 61, 665-676. [CrossRef] 
22. Charnigo, R.J.; Beidler, D.; Rybin, D.; Pittman, D.D.; Tan, B.; Howard, J.; Michelson, A.D.; Frelinger, A.L.; Clarke, N. PF-04447943, a Phosphodiesterase 9A Inhibitor, in Stable Sickle Cell Disease Patients: A Phase Ib Randomized, Placebo-Controlled Study. Clin. Transl. Sci. 2019, 12, 180-188. [CrossRef]

23. Harms, J.F.; Menniti, F.S.; Schmidt, C.J. Phosphodiesterase 9A in Brain Regulates CGMP Signaling Independent of Nitric-Oxide. Front. Neurosci. 2019, 13. [CrossRef]

24. Protein Data Bank I Nucleic Acids Research / Oxford Academic. Available online: https://academic.oup.com/nar/article/28/1/2 35/2384399 (accessed on 25 March 2021).

25. Madhavi Sastry, G.; Adzhigirey, M.; Day, T.; Annabhimoju, R.; Sherman, W. Protein and Ligand Preparation: Parameters, Protocols, and Influence on Virtual Screening Enrichments. J. Comput. Aided. Mol. Des. 2013, 27, 221-234. [CrossRef]

26. Frisch, M.J.; Trucks, G.W.; Schlegel, H.B.; Scuseria, G.E.; Robb, M.A.; Cheeseman, J.R.; Scalmani, G.; Barone, V.; Petersson, G.A.; Nakatsuji, H.; et al. Gaussian 16, Revision C.01; Gaussian, Inc.: Wallingford, CT, USA, 2016.

27. Tirado-Rives, J.; Jorgensen, W.L. Performance of B3LYP Density Functional Methods for a Large Set of Organic Molecules. J. Chem. Theory Comput. 2008, 4, 297-306. [CrossRef]

28. Wang, J.; Wang, W.; Kollman, P.A.; Case, D.A. Automatic Atom Type and Bond Type Perception in Molecular Mechanical Calculations. J. Mol. Graph. Model 2006, 25, 247-260. [CrossRef]

29. Forli, S.; Olson, A.J. A Force Field with Discrete Displaceable Waters and Desolvation Entropy for Hydrated Ligand Docking. J. Med. Chem. 2012, 55, 623-638. [CrossRef]

30. Abraham, M.J.; Murtola, T.; Schulz, R.; Páll, S.; Smith, J.C.; Hess, B.; Lindahl, E. GROMACS: High Performance Molecular Simulations through Multi-Level Parallelism from Laptops to Supercomputers. SoftwareX 2015, 1-2, 19-25. [CrossRef]

31. Lindorff-Larsen, K.; Piana, S.; Palmo, K.; Maragakis, P.; Klepeis, J.L.; Dror, R.O.; Shaw, D.E. Improved Side-Chain Torsion Potentials for the Amber Ff99SB Protein Force Field. Proteins 2010, 78, 1950-1958. [CrossRef]

32. Hess, B.; Bekker, H.; Berendsen, H.J.C.; Fraaije, J.G.E.M. LINCS: A Linear Constraint Solver for Molecular Simulations. J. Comput. Chem. 1997, 18, 1463-1472. [CrossRef]

33. Lemak, A.S.; Balabaev, N.K. On The Berendsen Thermostat. Mol. Simul. 1994, 13, 177-187. [CrossRef]

34. Bussi, G.; Donadio, D.; Parrinello, M. Canonical Sampling through Velocity Rescaling. J. Chem. Phys. 2007, 126, 014101. [CrossRef]

35. Darden, T.; York, D.; Pedersen, L. Particle Mesh Ewald: An N. $\log (\mathrm{N})$ Method for Ewald Sums in Large Systems. J. Chem. Phys. 1993, 98, 10089-10092. [CrossRef]

36. Sivakumar, D.; Kumar, V.; Naumann, M.; Stein, M. Activation and Selectivity of OTUB-1 and OTUB-2 Deubiquitinylases. J. Biol. Chem. 2020, 295, 6972-6982. [CrossRef] [PubMed]

37. Sivakumar, D.; Gorai, B.; Sivaraman, T. Screening Efficient BH3-Mimetics to HBcl-B by Means of Peptidodynmimetic Method. Mol. BioSyst. 2013, 9, 700-712. [CrossRef] [PubMed]

38. Kumari, R.; Kumar, R.; Lynn, A. G_mmpbsa-A GROMACS Tool for High-Throughput MM-PBSA Calculations. J. Chem. Inf. Model. 2014, 54, 1951-1962. [CrossRef] [PubMed] 